\title{
Impacts of the Implementation of a Project Management Information System - a Case Study of a Small R\&D Company
}

\author{
Mirjana Kljajić Borštnar, Andreja Pucihar
}

\author{
University of Maribor, Faculty of Organizational Science, Kidričeva cesta 55a, Slovenija, \\ mirjana.kljajic@fov.uni-mb.si. andreja.pucihar@fov.uni-mb.si
}

\begin{abstract}
Background: The problems of resources management (human, financial, time) in multi-project companies are inherently complex and need to be addressed systematically, in both small and large organizations. Furthermore, there is a need for transparent communication and collaboration within the organization as well as with partnering organizations. There are many methodologies and tools supporting project management, which are themselves complex and are therefore not widely adopted, especially among small companies.

Objectives: The aim of this paper is to analyse impact of the implementation of a flexible cloud-based project management information system (PMIS) from the human resources, financial management, and collaboration points of view.

Method: We have conducted a case study in a small Slovenian research and development company, that has implemented the 4PM PMIS.

Results: The findings imply the importance of keeping the balance of the creative processes that are unstructured, rule free and even chaotic, with structured processes monitor and control.

Conclusions: The results of the study suggest that the use of "4PM" in support of multi-project management improves human resources and financial management in a collaborative and transparent way when implemented in an open and highly motivated environment.
\end{abstract}

Keywords: multi-project management, project management information system, systems approach, small organization

\section{Introduction}

Contemporary organizations are increasingly project oriented. Gareis and Huemann (2003) refer to such organizations as Project-oriented Companies (POC), which acknowledge project management as an organizational strategy, manage a project portfolio of different project types and are organized to provide integrative functions. Furthermore, the projects represent their core business. Projects are interrelated within the organization through human resources, finances, and time planning. In contrast, people are assigned to other activities and tasks, which also consume their time (and other resources) and which are not accounted for within the specific project. If not properly governed, such organizations end up with weak organizational climates, high fluctuation rates, as well as low productivity and efficiency.

In previous decades, research on project management was primarily focused on single-project management (Ali and Money, 2005; Ali, Anbari and Money, 2008; Raymond and Bergeron, 2008; Lindkvist, Söderlund and Tell, 1998; Lundin and Söderholm, 1995; Shenhar and Dvir, 1996). There is a substantial body of knowledge on the methodologies and tools used to support project management, from its traditional form to more agile ones (Kerzner, 2003; PMI, 2001). Recently, the focus has shifted towards multi-project management (Van der Merwe, 1997; Packendorff, 1995; Nandhakumar and Jones, 2001; Engwall and Jerbrant,

Received: $30^{\text {th }}$ August 2013; revised: $16^{\text {th }}$ October 2013; accepted $19^{\text {th }}$ November 2013 
2003; Cusumano and Nobeoka, 1998; Elonen and Artto, 2003, Zika-Viktorsson, Sundström and Engwall, 2006; Mortensesn, Woolley and O'Leary, 2007). However, many of those studies are addressing an a priori portfolio composition, which only addresses the priorities set to the single projects and resources on a strategic level (also referred to as 'project portfolio management' and 'program management'). However, the term 'multi-project management' refers to the simultaneous managing of several projects on the operational level with the aim of the successful functioning of a single project and overall organizational success, which represents an overwhelming burden on the project and especially general managers.

Evaristo and Fenema (1999) proposed a new categorization from the number of projects and locations, i.e. a new model identifying complex multi-projects on multiple locations that can be either distributed or shared.

The problems of resource allocation (human, financial, time) in organizations with multiple concurrent projects are inherently complex. Engwall and Jerbrant (2003) studied resource allocation and suggested that there is a need to address this issue as a deeper organizational feature embedded in a multi-project organizational setting. Geraldi (2007) addressed complexity in multi-project organizations as an ability of these companies to deal with the coexistence of order and chaos. She proposed four organizational archetypes: the creative-reflective, the mechanic-structured, the chaotification of order, and the bureaucratization of chaos. This means that multi-project organization has specific needs in terms of supporting creative work process while keeping the structured processes. Resource allocation is not the only challenge in the multi-project environment. Turner, Ledwith and Kelly (2012) addressed the problem of the multi-tasking and multi-disciplinarity of the project teams' members. Ratcheva (2009, pp. 207) argues that multidisciplinarity can ' $[. .$.$] facilitate team members in articulat-$ ing diverse knowledge perspectives'. A different view was researched by Mortensen et al. (2007), who discussed multiple team memberships. Where the classic project management approach assumes one person assigned to one project, modern practices assume one person assigned to a number of projects. Their study implies that the crucial role for team success is the selection of appropriate team members, information sharing and communication within and across teams and in the organization of work. When team members are working across time, space and organizational boundaries and their work is supported by information and communication technology, the phrase 'virtual teams' is used (Lipnack, 2000, pp. 352).

Different geographical locations of the team members account for differences in physical location, time zones, cultures and values (Lee-Kelley and Sankey, 2008; Groznik, Weber and Kern, 2011). The human resources allocation problems regarding perspectives on multi-disciplinarity, multi-team membership, and virtual teams were discussed in (Evaristo and Fenema, 1999; Payne and Turner, 1999; Hendriks, Voeten and Kroep, 1999), in which the authors suggested different approaches to gaining control and reducing risk of insufficient human resources management. In contrast, the results of a study by Zika-Viktorsson, Sundström and Engwall (2006, pp. 391) suggested that the problem of human resources allocation is far more complex and cannot be solved in a prescriptive way. Furthermore, Zika-Viktorsson, Sundström and Engwall, (2006, pp. 391) identified that project overload arising from insufficient human resources allocation ' $[. .$.$] is associated with impaired$ performance (measured in terms of poor adherence to time schedules), high levels of psychological stress reactions, and decreased competence development'.

Owing to the above-explained complexities of human resources management (competencies and time allocation), financial management (financial resources allocation), and quality management, several authors have suggested a need for efficient information and communication support (Ahleman and Riempp, 2008; Kaiser and Ahlemann, 2010; Caniëls, Ralph and Bakens, 2012; Mortensen et al., 2007).

The basic presumption in the management of complex dynamic systems is that the system can be observed and controlled by feedback information (Kljajić Borštnar, Kljajić, Škraba, Kofjač and Rajkovič, 2011). Furthermore, not only feedback, but also anticipative information is necessary for the efficient management of a complex system. The information system (IS) plays the most important role in all living and technical systems. It provides communication among elements and environments in the course of achieving goals. Without feedback and anticipative information, the functioning and developing of the systems would be impossible. However, depending of the nature of the systems, there are enormous differences among the types and complexities of IS. Therefore, the basic role of information systems must be to provide the right information when needed. Nevertheless, information alone is insufficient for successful decision making. Decision processes in organizational systems are primarily based on the participating subjects.

Nowadays, information systems are mainly computerbased systems. They are a combination of hardware, software, infrastructure and employees, organized to facilitate various tasks and activities in an organization. In a broad sense, a definition of 'information system' is used to refer not only to the information and communication technology (ICT) that an organization uses, but also to the way in which people interact with this technology in support of business processes. Any specific information system aims to support planning, operations, management and decision making (Kroenke, 2008). Information systems cover various areas of organizations; some support only particular functional areas of organizations (e.g. financial, marketing, production, and human resource management information systems), some support entire functional areas of organiza- 
tions (e.g. enterprise resource planning systems) and others support the networks of organizations (e.g. supply chain management information systems) (Rainer, Turban, Potter and Cegielski, 2010). Enterprise (wide) resource planning systems (ERP systems), supporting all functional areas and business processes of organization (developed in the late 1980s) (Rashid et al., 2002) have been widely adopted by large and medium-sized organizations (Bernroider, Sudzina and Pucihar, 2011).

Project Management Information Systems (PMIS) are still used partially, mainly single-project-management oriented, lacking holistic support of all business processes of multi-project oriented organizations, and according to Dahlgren and Söderlund (2010) and Raymond and Bergeron (2007, pp. 3) 'the wider and fundamental issues of organization-wide coordination and control between projects need to be addressed'.

Issues of complexity, chaos vs. order and multi-project interdependencies are especially difficult to address in small and medium-sized companies (Turner, Ledwith and Kelly, 2012, Ernø-kjølhede, 2000). Our study will focus on a small and medium-sized research and development (R\&D) company in particular. These kinds of organizations rely on acquiring projects and successful execution of projects from various sources of private and public financiers). Furthermore, there is a need for transparent communication and collaboration within the organization as well as with partnering organizations. To be able to successfully manage different projects (in type, funding, scope, scale) while simultaneously keeping people motivated and creative, these challenges need to be addressed systematically. There are many methodologies and tools, (e.g. Traditional Approach, PRINCE2, Critical Chain Project Management, Event-Chain Methodology, Process-Based Management, Agile Project Management, Lean Project Management, etc.) supporting project management, which are themselves complex and are therefore not widely adopted, especially among smaller organizations. Furthermore, the new ways of working require flexibility from organizations and people in the way of planning the work, monitoring and controlling the work, and overcoming various communication and collaboration challenges and cultural differences. So-called virtual teams, acting in various cultural, language, time, and interdisciplinary environments collaborate on various projects (e.g. new product, service, and knowledge development) in a virtual environment, without having even one face-to-face meeting. Another challenge in such projects is in efficient knowledge transfer within the financial and time limits of the given project. The problem of time limitations and overload, affecting the knowledge transfer and hence the individual and organizational development was addressed by Zika-Viktorsson, Sundström and Engwall (2006).

While project managers must provide transparent and efficient planning, monitoring and controlling of resources in order to achieve the project goals, top management must have an overview of the company as a whole (Martinsuo and Lehtonen, 2006). The use of an integral information system that efficiently supports all aspects of multi-project oriented organization is thus essential.

We have conducted a case study in a small Slovenian research and development company using the 4PM webbased project management information system. The aim of this qualitative study is to analyse the process of implementation and assess the impact of the implementation of a flexible cloud-based project management information system from the human resources, financial management, and collaboration points of view in a small R\&D organization.

\section{Methodology}

\subsection{Description of the company}

We have conducted a single case study in a small Slovenian research and development (R\&D) ICT company. It is a typical, small R\&D multi-project company, established in 2003. It has 58 employees, of which $85 \%$ are male. The average age of the employees is 32 . The employees' educational structure is $10 \% \mathrm{PhD}, 10 \% \mathrm{MSc}$, and the remaining having bachelor's degrees. The management structure includes a CEO and managing director at the top and three department directors on the second level of decision-making. The yearly turnover is about $€ 3.15$ million. Their main income comes from R\&D projects financed by national and EU funding, and commercial software development projects. At the time of the study, they were running five EU projects as a partnering organization, and over 30 commercial software development projects.

Mission statement from the company's CEO:

We try to create a stimulating environment in which high-quality and innovative technology products are being developed. From the outset, we have strived to maintain a democratic organizational structure and a culture built on trust, where everyone adds his part of the puzzle.

The company soon realized that they would need a holistic and systematic approach for managing the large number of projects to support financial planning, human resource planning (task delegation according to competences and time), documentation archiving, monitoring and controlling, and reporting. The company was a typical example of a multi-project organization with clearly identified needs that must be addressed in a systematic way; it was therefore an appropriate case to be studied.

The single-case study was used as a research strategy to examine three main aspects of use of the 4PM project management information system in a multi-project-oriented organization, i.e. human resources, finance planning and collaboration aspects. The research was conducted in four 
stages (Yin, 2003): designing, conducting, analysing the evidence, and developing the conclusions, recommendations and implications.

\subsection{Design of the study}

This study was designed to address both of the possible applications for a case study model (Yin, 2003): firstly, to describe the real-life context in which intervention has occurred and, secondly, to describe the intervention itself.

The real-life context refers to the problems related to the scope and nature of the company's multi-project operations. For the observations and investigation of the current and desired situations, we used soft systems methodologies (SSM), in particular the seven-stage approach (Checkland, 1999):

1. Entering the problem situation,

2. Expressing the problem situation,

3. Formulating root definitions of relevant systems,

4. Building conceptual models of human activity systems,

5. Comparing the models with the real world,
6. Defining changes that are desirable and feasible,

7. Taking action to improve the real world situation.

The intervention refers to the process of implementation of the 4PM PMIS, which is presented in Figure 1: User Requirements, Pilot Use, and Full Implementation. Throughout the process of implementation, the evaluation, based on user feedback, was monitored. The feedback was used to adjust the functionalities of the PMIS and to gain insight into the implementation process from the research point of view. Evidence was gathered by using triangulation data collection methods, done in accordance with the PMIS implementation phases. The following instruments were used (Yin, 2003): direct and participant observations, interviews, and documentation.

In the User Requirements phase, the PMIS functionalities (user groups, classifications, reports and performance measures) were aligned to the organizational goals with the observation of participants, documents analysis and interviews. In the second phase (Pilot Use), the implementation plan was developed. The corporate policy on the use of the

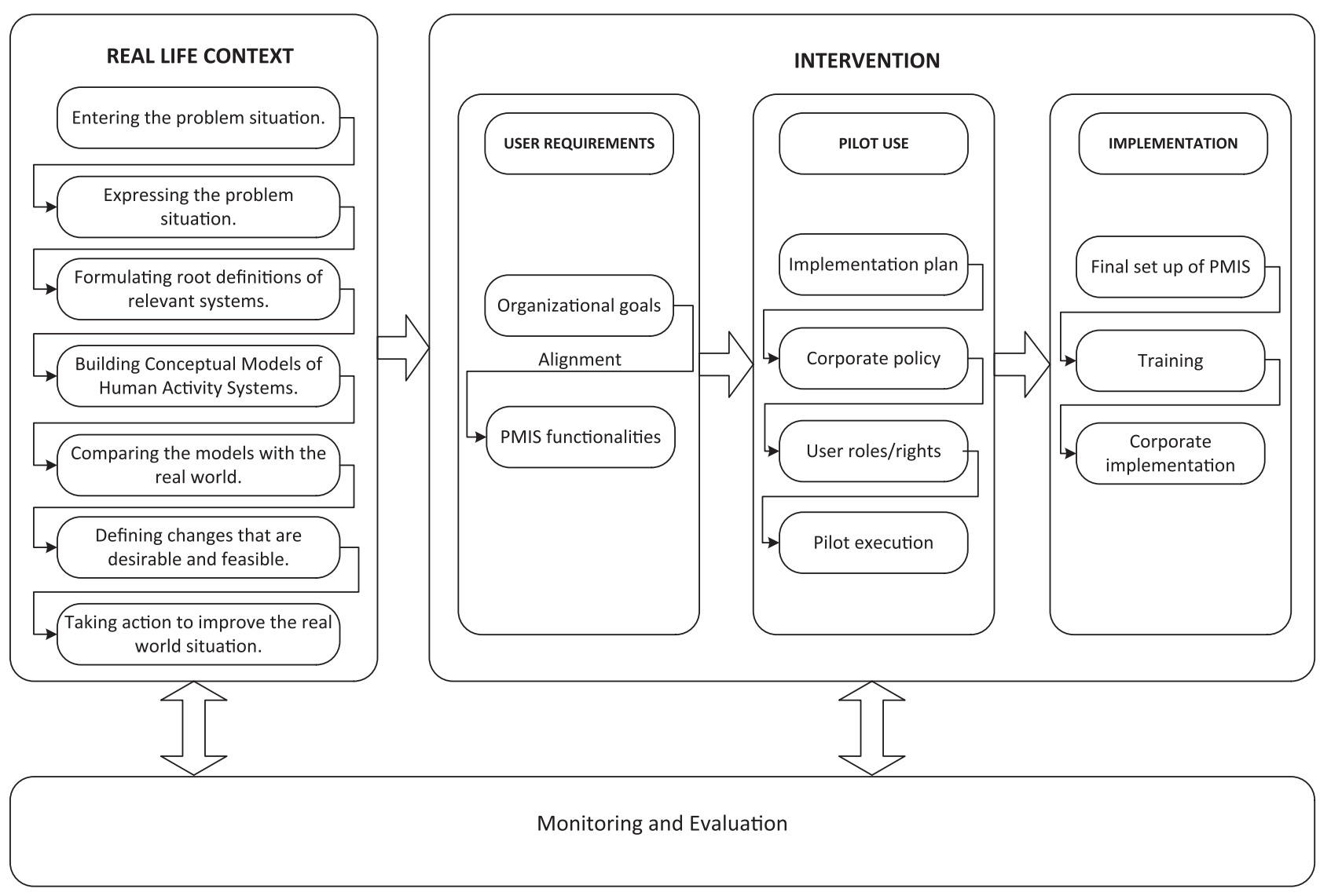

Figure 1: Research design 
PMIS was set, and user and access rights were prepared. A smaller scale test use was done with a limited number of participants and projects. The group consisted of one administrator and three researchers, of which one assumed the role of project manager; top management also participated in the test use. Feedback information was collected by observation and interviews with the test users. Adjustments of the PMIS functionalities (taxonomy, access rights and reports) were done based on the feedback from the test users.

In the phase of full implementation, the final setup of 4PM PMIS was installed based on the pilot use. Before the corporate implementation was rolled out, the users received training on the use of PMIS. Feedback information was again collected from the users and several adjustments to the PMIS were made. Finally, the processes and users opinions were analysed via observation and interviews after the 4PM PMIS was in use for six months.

\subsection{Conducting the study}

The study was conducted within a total time span of one year. During that period, all the phases in Figure 1 were executed. In the study, we examined both the real life context using Checklands' soft system methodology (1999), as well as the intervention, which can be best described as a Project Life Cycle with specific stages defined by the PMIS provider together with the company (see Figure 1). Semi-structured interviews with top management, project managers, researchers and administrative workers were conducted during problem identification, test use, and post implementation. Interviews were designed around three main aspects: employee satisfaction, financial management and collaboration.

Employee satisfaction aspect was examined around the following topics:

- Does the PMIS cover all data and information needs?

- Is the PMIS easily accessible?

- Is the user interface intuitive?

- How long did it take to get used to navigating the PMIS?

- Does it take you less time to complete reporting on work completed?

- General opinion about the use of the 4PM PMIS.

The aspect of financial management was considered through the following topics:

- Does the PMIS cover all data and information needs?

- Is the communication with the accountant more efficient?

- Do you have better overview of individual project finances?

- Do you have better overview of overall organizational finances?

Collaboration aspect in light of the PMIS was examined through the following topics:
- Are you better informed about the projects' undertakings?

- Do you feel better connected to your colleagues?

- Can you better access company's knowledge?

- Do you feel you have better overview of the whole organization?

The interviews were recorded and coded by the interviewees' status (administration, project manager, researcher, top management) and the time of interview (occurring at the beginning of the implementation process, during, and postimplementation).

Beginning of the implementation processes (participants' observation, interviews, document analysis)

In an interview with the top management, we identified key problems, goals and processes that needed to be supported. In a small company, top management is actively involved in the work processes, and they rely on a democratic and open working relations based on transparent communication. However, they expressed the need to support the creative work by structured processes that can be monitored and controlled. Priority was given to the public co-funded projects, with their strict reporting requirements. Furthermore, the need for a gradual implementation of the PMIS was noted. Project managers are in fact researchers, many times lacking specific competencies on project management. Therefore, it was vital to implement the PMIS gradually, so that employees can acquire knowledge and skills for using it. Based on the initial interviews, document analysis and observation, the personalized database taxonomy (classification) was developed, taking into account specific needs of the company, such as internal projects and tasks classifications. In total, ten interviews were conducted in this phase.

During the implementation process (interviews, feedback information, adjustment)

A test user group consisting of the CEO, two researchers, one researcher taking the role of a project manager, and one administrative worker were trained for the use of the 4PM PMIS. An administrative worker took care of the initial data input. First, they started using the financial module, and later the document management system and collaborative environment. The latest stage of this phase was the introduction of the non-project related module related to human resources management (leave planning, absence, travels, appraisals etc.). In total, four interviews were conducted at this phase.

Post Implementation (feedback information, processes analysis, participants' observation, and post implementation interviews)

After the 4PM PMIS was introduced and used for six months across the organization, interviews with the top 
management, project managers, researchers, and administration workers were conducted, and the impact of implementation was assessed. In total, nine interviews were conducted at this phase.

\section{Findings}

The problems described by the participants of the study are common to many SMEs, especially in times of accelerated growth of projects and employees. Current management practice drawn from traditional project management proves to be inadequate. Experts in certain business domains usually lack knowledge of human resources management, financial management, and other competences important for successful project management. The complexity of multi-project organization is reported to be overwhelming and the need for systematic IT support had been identified on the project management and top management levels. Participants clearly identified three key areas that need to be supported by the PMIS:

- Human resources management (work load planning, task delegation, task acceptance, reporting of time spent on a task, evaluation of performance, communication and collaboration);

- Financial management on both single project as well as overall organizational level (revenue planning, inflow planning, costs planning, cash flow planning, cost controlling, reporting); and

- Overall multi-projects management on a strategic level.

Both observation and document analysis supported the findings of the interviews with project managers in which it was state that they were overloaded by the project administration. This was mostly related to reporting to the management and financiers.

Three groups of users were identified according to their needs for IT support:

- Top management, who must communicate accurate and up-to-date information to the project managers about changes and risks, upon which the project managers would rely for the decision-making about the project. Top management must have an aggregated overview of critical business information (cash flow, performance indicators, etc.);

- Project managers, who must be supported in their everyday project activities (task delegation and control, controlling the financial plan execution, reporting),

- Members of the project team, who need an operating platform supporting the project structured and unstructured communication, and documentation management.

The basic idea of the company management was that every member of the project team should participate in the quest for positive project results, should collaborate and communicate with all members of the team, providing transparent insight into the state of the project, reporting about the work done, time spent, and other relevant data about the project. Furthermore, the company was looking for a flexible solution that would contribute to learning and thus strengthening the project management (and other) competencies of the managers and team members. The solution should provide efficient decision-making about priorities, based on the systems overview throughout the whole company.

\subsection{Human Resources Management}

The productivity of employees working on multiple projects concurrently is difficult to assess. The reported time spent on a task and the effective time are frequently not the same. Furthermore, the requirements for reporting to financiers, especially on international projects, do not show the real status of the hours spent on a task.

There are four concepts related to work time: 1) planned time, 2) reported time by an employee, 3 ) approved time by a project manager, and 4) reported time to the financiers. The PMIS is supporting dynamic work planning according to the overview of the actual time allocated to specific tasks (Kobal, 2009) and reporting about the time spent on a task. Additionally, the agreed effective time and content of work done can help better workload distribution, transparent rewarding of employees, and finally greater employee satisfaction and motivation for work. Therefore, the basic role of the 4PM PMIS was in supporting of the process of dynamic work planning with monitoring and controlling, and transparent rewarding of employees. This process is best described as a democratic process of reporting the subjective judgment of time spent on a specific task, and communication and negotiation about the effective time acknowledged, qualitative and quantitative work assessment, absence planning, work load planning, etc. It was of great importance that the top management was actively participating in promoting the culture of reporting, monitoring and controlling of the time spent on tasks, and the quality assessment of the work done.

Although a flexible solution, it should provide standardized and, where possible, automated handling of the following activities: task delegation, time allocation, automated notification of changes, documentation handling and report preparation. Structured and standardized processes, maintaining flexibility for the task scheduling, are crucial in the efficient support of all participants in the process and allow participants to be focused on goals rather than administration. At the same time, all three groups of users have feedback and anticipative information when needed.

There are two instances of reporting needed: one for management and other for financiers. Well-defined and supported processes offer higher reliability in the preparation of various reports (scheduled reports, ad hoc reports and analy- 
sis) based on coherent and reliable data. Furthermore, connectivity to other information systems, such as accounting IS, and human resources management IS, would contribute to better efficiency in planning, monitoring and controlling of not merely the human resources processes, but all business processes. Furthermore, reports on the analysis of the work planned vs. work done in yearly appraisals revealed some interesting information that can help to better manage the human resources. By comparing planned and completed work, management can assess the performance, task and time allocation adequacy, and the aspirations of the employees. Based on the historical data, predictions can be made for workload planning as well.

The need for handling unpredicted situations, that require relocating resources and prioritizing tasks, is supported by the overview of the whole organization provided by PMIS. However, not only the information about the current and predicted workload distribution is sufficient, the task delegation is supported in a collaborative way. Each member has the right to accept or decline the task due to other prioritized tasks. Open communication within and outside the project team is vital, but focused and facilitated discussion is also supported. Together, they contribute to better employee involvement and collaboration, and fewer conflicts. Transparency of processes, based on systematic feedback information at all levels of decision-making (operational-task realization, tactical-goal achievement, and strategic-overall performance success) leads to better motivation of employees, transparent performance assessment of employees, and knowledge transfer between the project members and between projects.

\subsection{Financial management}

Financial management in a multi-project organization is complex due to limited financial resources, unpredictable costs, different currencies, specific financial reporting requirements of individual financiers, possible large investments before receiving of funds, travelling expenses, etc. The basic challenge is cash flow planning. Usually, the costs occur before the cash inflow; it can happen that large costs occur in several projects during the same time period; therefore, the need for planning the cash flow is crucial for business. Personnel costs represent the largest part of the budget; therefore, it was crucial to connect work planning and reporting (based on different hourly rates related to a specific project) with the accounting IS.

One of the requirements of the organization was to maintain the existing accounting IS (especially with accounts payable and receivable); therefore, integration with the PMIS was needed. Information on cash inflows and outflows should be available when the event occurs; this was explicitly stated by project managers. The project management view of financiers usually differs from the accounting view; therefore, this communication was improved with the implementation of the PMIS.

Another explicit requirement, indicated from the interviews with the top management, was the need for financial overview across projects in terms of planning, and controlling the cash inflows and outflows. Only in this way can management anticipate risks and critical events and make timely decisions accordingly.

The major challenge in integrating the two information systems was not technological, but organizational. This is also the case in many other similar organizations where employees not directly involved in the project work have difficulties comprehending the nature of such work. Furthermore, the data structure (aggregation level), format and time had to be aligned in order to provide suitable information to the designated person in time.

\subsection{Collaboration aspect}

Collaboration was one of the three main aspects identified by the top management, project managers, and team members. Along financial and human resources management, collaboration is crucial in the success of the heterogeneous R\&D project teams. Teamwork encompasses open, focused and documented communication, and knowledge transfer. Knowledge can be stored in documents, communication (formal, informal, tacit and implicit), and there is always tacit knowledge hidden within the project groups.

For the organization in question, the $\mathrm{R} \& \mathrm{D}$ groups are heterogeneous in existing within and outside the organization, being multidisciplinary (programmers, systems engineers, web programmers, designers, administrative workers, and others), multicultural, and multilingual. The work is frequently located off of the company premises, sometimes team members never meet face to face. For this reason, the collaboration platform should provide support for efficient communication among the team members and structured and transparent communication and document management between project team members.

The participants of the study indicated the need for efficient document management. Integrated with a collaboration platform, this forms a powerful knowledge management tool encompassing the following functionalities:

- Prepared templates and reports (with comments, documents and files and folders structure),

- Learning platform for within and between project knowledge transfer (time plans, various reporting options, standardized contract drafts, technical specifications, minutes of meetings, etc.).

- Standardized and centralized documents capturing, archiving, organized by projects

- Versioning (locking, access rights, work on the latest version),

- Control of access rights, 
- Teamwork support (sharing, editing/reading rights, advanced search options).

In setting up an efficient collaboration information system that encompasses the monitoring of the document workflow, the project manager determines what information is needed by the three groups of users (general management, project manager, team member), the document flow within the project group and with the other stakeholders. Again, the balance between the formal (structured) communication and informal (unstructured) communication was the basis for creative and open collaborative work.

\section{Conclusions}

Increasing numbers of organizations are facing the complexity of multi-project management. Research on this subject is scarce, mainly focusing on specific aspects or single project management information support. We analysed the impact of implementation of a flexible cloud-based project management information system in a small Slovene R\&D company, from the human resources, financial management, and collaboration points of view. For this purpose, we conducted a single-case study. Evidence in the three implementation phases was gathered using semi-structured interviews, document analysis and participants observations.

$R \& D$ groups are a set of creative people developing innovative solutions, but they have to be able to work with different stakeholders (financiers, part time workers, managers, and external partners). Furthermore, they have to follow strict project rules set by the financier, such as time plans, reporting, documenting, especially for complex national and EU funded projects. Working on a project very frequently means having flexible working hours, with peaks greatly exceeding 40-hour working weeks. The evidence revealed the importance of a systematic approach to supporting key areas of project management processes assessed by the companies' top managers and project managers. The findings support the proposed theory of keeping the balance of the creative processes that are unstructured, rule free and even chaotic, with structured processes to monitor and control them (Geraldi, 2007).

Furthermore, the evidence revealed that the key to successful multi-project management is in the efficient support of the employees by empowering them in the process of work planning and reporting, transparent work evaluation and open communication. The results of the study suggest that the use of 4PM PMIS in support of multiple project management improves human resources and financial management in a collaborative and transparent way.

The most important lesson learned is about the process of implementation of a project management information system. The process of implementation itself should be transparent, the roles of individuals clearly defined, and the implementation plan aligned with the organization strategies and internal rules. Finally, the organizations' top management has to support this quest in setting an example and creating conditions for the organizational culture to evolve in a way that each employee will adopt the system.

The drawback of this study is in the selection of one company whose organizational culture was already project oriented. Future research should thus focus on examining other types of organizations (bigger, bureaucratic, with more hierarchy levels, private and public).

\section{Acknowledgements}

This research was funded by the Slovenian Research Agency; Program No. P5-0018. We are also grateful to the studied company and the PMIS provider, who were willing to participate in this study by providing research material and insights into their business processes.

\section{References}

Ahlemann, F. \& Riempp, G. (2008). A Conceptual Reference Model for Project Management Information Systems. Wirtschaftsinformatik, 50(2), 88-97, http://dx.doi.org/10.1365/ s11576-008-0028-y

Ali, A.S.B. \& Money, W.H. (2005). A Study of Project Management System Acceptance. Proceedings of the 38th Annual Hawaii International Conference on System Sciences (HICSS'05), Vol. 8, pp. 234c, http://dx.doi.org/10.1109/HICSS.2005.53

Ali, A.S.B., Anbari, F.T. \& Money, W.H. (2008). Impact of organizational and project factors on acceptance and usage of project management software and perceived project success. Project Management Journal, 39(2), 5-33, http://dx.doi. org/10.1002/pmj.20041

Bernroider, E.W.N., Sudzina, F., Pucihar, A. (2011). Contrasting ERP Absorption Between Transition and Developed Economies From Central and Eastern Europe (CEE). Information Systems Management, 28(3), 240-257, (Special Issue: Information Technology in Transition Economies), http://dx.doi.org/10.1080/10580530.2011.585581

Checkland, P. (1999). Systems Thinking, Systems Practice: Includes a 30-Year Retrospective. Chichester: John Wiley and Sons Ltd.

Cusumano, M. \& Nobeoka, K. (1998). Thinking beyond lean: how multi-project management is transforming product development at Toyota and other companies. New York: Free Press.

Dahlgren, J. \& Söderlund, J. (2010). Modes and mechanisms of control in multi-project organizations: the R\&D case. International Journal of Technology Management, 50(1), 1-22, http://dx.doi.org/10.1504/IJTM.2010.031915

Elonen, S. \& Artto, K.A. (2003). Problems in managing internal development projects in multi-project environments. International Journal of Project Management, 21(6), 395402, http://dx.doi.org/10.1016/S0263-7863(02)00097-2

Engwall, M. \& Jerbrant, A. (2003). The resource allocation syndrome: the prime challenge of multi-project management? 
International Journal of Project Management, 21(6), 403409, http://dx.doi.org/10.1016/S0263-7863(02)00113-8

Ernø-Kjølhede, E. (2000). Project Management Theory and the Management of Research Projects. MPP Working Paper No. 3/2000, Copenhagen Business School. Retrieved July 7, 2013, from http://openarchive.cbs.dk/bitstream/handle/10398/6308/ wp32000.pdf? sequence $=1$.

Evaristo R. \& Fenema P.A. (1999). Typology of project management: emergence and evolution of new forms. International Journal of Project Management, 17(5), 275-81.

Gareis, R. \& Huemann, M. (2003). Project management competencies in the project oriented company. In Turner, J.R. (ed.), People in project management, Aldershot: Gower.

Geraldi, J.G. (2008). The balance between order and chaos in multi-project firms: A conceptual model, International Journal of Project Management, 26(4), 348-356, http:// dx.doi.org/10.1016/j.ijproman.2007.08.013

Groznik, A., Weber, P. \& Kern, T. (2011). Assessing organizational virtuality. African Journal of Business Management, 5(8), 3132-3138, http://dx.doi.org/10.5897/AJBM10.348

Hendriks, M.H.A., Voeten, B. \& Kroep, L. (1999). Human resource allocation in a multi-project R\&D environment. International Journal of Project Management, 17(3), 181-188, http:// dx.doi.org/10.1016/S0263-7863(98)00026-X

Kaiser, M.G., Ahlemann, F. (2010). Measuring Project Management Information Systems Success: Towards a Conceptual Model and Survey Instrument. ECIS 2010.

Kerzner, H. (2003). Project management, A systems approach to planning, scheduling and controlling. New York: John Wiley and Sons.

Kljajić Borštnar, M., Kljajić, M., Škraba, A., Kofjač, D., Rajkovič, V. (2011). The relevance of facilitation in group decision making supported by a simulation model. System Dynamics Review, 27(3), 270-293, http://dx.doi.org/10.1002/sdr.460

Kobal, M. (2009). Agilno vodenje projektov z uporabo umetne inteligence, Dnevi slovenske informatike, 15-17 april 2009.

Kroenke, D. M. (2008). Experiencing MIS. Upper Saddle River, NJ: Prentice Hall,.

Lee-Kelley, L. \& Sankey, T. (2008). Global virtual teams for value creation and project success: A case study. International Journal of Project Management, 26(1), 51-62, http://dx.doi. org/10.1016/j.ijproman.2007.08.010

Lindkvist, L., Söderlund, J. \& Tell, F. (1998). Managing Product Development Projects: On the Significance of Fountains and Deadlines. Organization Studies, 19(6), 931-951, http:// dx.doi.org/10.1177/017084069801900602

Lipnack, J. (2000). Virtual Teams: People Working Across Boundaries with Technology. New Yirk: John Wiley \& Sons, pp. 352.

Lundin, R. A. \& Söderholm, A. (1995). A Theory of the temporary organization. S)candinavian Journal of Management, 11(4), 437-455, http://dx.doi.org/10.1016/0956-5221(95)00036-U

Marjolein, C.J., Caniëls, R. \& Bakens, J.J.M. (2012). The effects of Project Management Information Systems on decision making in a multi project environment, International Journal of Project Management, 30(2), 162-175, http://dx.doi. org/10.1016/j.ijproman.2011.05.005

Martinsuo, M. \& Lehtonen, P. (2007). Role of single-project management in achieving portfolio management efficiency, International Journal of Project Management, 25, 56-65, http://dx.doi.org/10.1016/j.ijproman.2006.04.002
Mortensen, M., Woolley, A. W., \& O’Leary, M. B. 2007. Conditions Enabling Effective

Multiple Team Membership. In K. Crowston, S. Sieber, \& E. Wynn (Eds.), Virtuality and

Virtualization, Vol. 236, pp. 215-228. Boston: Springer

Nandhakumar, J. \& Jones, M. (2001). Accounting for time: managing time in project-based teamworking. Accounting, Organizations and Society, 26(3), 193-214, http://dx.doi. org/10.1016/S0361-3682(99)00051-3

Packendorff, J. (1995). Inquiring into the Temporary Organization: New Directions for Project Management Research. Scandinavian Journal of Management, 11(4), 319-334, http:// dx.doi.org/10.1016/0956-5221(95)00018-Q

Payne, J.H. \& Turner, J.R. (1999). Company wide project management: the planning and control of programmes of projects of different types. International Journal of Project Management, 17(1), 55-59, http://dx.doi.org/10.1016/S02637863(98)00005-2

Project Management Institute - PMI. (2001). A guide to the Project Management Body of Knowledge (PMBok). Newtown Square.

Rainer, R. K., Turban, E., Potter, R. E. \& Cegielski, C. G. (2010). Introduction to Information Systems: Enabling and Transforming Business (Third Edition). New York: John Wiley \& Sons.

Ratcheva, V. (2009). Integrating diverse knowledge through boundary spanning processes - The case of multidisciplinary project teams, International Journal of Project Management, 27(3), 206-215, http://dx.doi.org/10.1016/j.ijproman.2008.02.008

Raymond, L. \& Bergeron, F. (2008). Project management information systems: An empirical study of their impact on project managers and project success, International Journal of Project Management, 26(2), 213-220, http://dx.doi.org/10.1016/j. ijproman.2007.06.002

Shenhar, A. \& Dvir, D. (1996). Toward a typological theory of project management. Research Policy, Vol. 25(4), 607-632, http://dx.doi.org/10.1016/0048-7333(95)00877-2

Turner R., Ledwith A. \& Kelly J. (2012). Project management in small to medium-sized enterprises: Tailoring the practices to the size of company, Management Decision, 50(5), 942 - 957, http://dx.doi.org/10.1108/00251741211227627

Van der Merwe, A.P. (1997). Multi-project Management - organizational structure and control. International Journal of Project Management, 15(4), 223-233, http://dx.doi.org/10.1016/ S0263-7863(96)00075-0

Yin, R.K. (2003). Case study research: Design and methods (3rd ed.). Thousand Oaks, CA: Sage.

Zika-Viktorsson, A., Sundström, P. \& Engwall, M. (2006): Project overload: An exploratory study of work and management in multi-project settings. International Journal of Project Management, 24(5), 385-394, http://dx.doi.org/10.1016/j. ijproman.2006.02.010

Mirjana Kljajić Borštnar holds a Ph.D. in the area of Information Systems Management from the University of Maribor. Her research work covers expert systems, multi-criteria decisionmaking, and Information Systems development methods. She holds a position of an Assistant Professor and is a member of Laboratory for Decision Processes and Knowledge-Based Systems. Her recent research work is focused on experiments with decision groups applying system dynamics simulators in 
experimental, interactive learning, and living laboratory environments. She is involved in several EU and industry projects. She is the author and co-author of several scientific articles published in recognized international journals including Group Decision and Negotiation and System Dynamics Review. She is also a program committee chair of annual international Bled eConference (http://BledConference.org).

Andreja Pucihar holds a Ph.D. in the area of Information Systems Management from the University of Maribor. Her research work is mainly focused to e-business, new e-business models, social media and web 2.0, living labs and open innovation. She has published over 130 papers in journals and conference proceedings, including in Electronic Markets, The International Journal on Networked Business and Information Systems Management. She holds a position of an Assistant Professor and is a member of E-business laboratory. She is involved into several EU and industry projects. She is a member of the boards of the following international journals: "Electronic Markets - The International Journal on Networked Business «, "Journal of Theoretical and Applied Electronic Commerce Research « and »International Journal of Information Systems \& Social Change«. She is also a program committee chair of annual international Bled eConference (http://BledConference. org). 